\title{
Hints of an Eoarchean magnetic field from the Isua Supracrustal Belt
}

\author{
C.I.O. NICHOLS ${ }^{1 *}$, B.P. WEISS ${ }^{1}$, A. EYSTER ${ }^{1}$, A.C.
} MALOOF $^{2}$, T. GREENFIELD ${ }^{3}$, N.M. KELLY ${ }^{4}$, M. ZAWASKI ${ }^{4}$, S.J. MOJZSIS ${ }^{4}$, E.B. WATSON ${ }^{5}$, D.J. CHERNIAK ${ }^{5}$

(*correspondence: cion2@mit.edu)

${ }^{1}$ Department of Earth, Atmospheric and Planetary Sciences, Massachusetts Institute of Technology

${ }^{2}$ Department of Geosciences, Princeton University

${ }^{3}$ Department of Earth Sciences, University of Cambridge

${ }^{4}$ Department of Geological Sciences, University of Colorado Boulder

${ }^{5}$ Department of Earth and Environmental Sciences, Rensselaer Polytechnic Institute

Understanding the earliest history of the geodynamo is important for constraining the early thermal and geodynamic history of our planet and establishing the role of planetary magnetic fields for habitability.

Extracting ancient records of Earth's field is extremely challenging due to the paucity of a well-preserved rock record. As such, evidence of Earth's field older than 3.5 billion years $(\mathrm{Ga})$ is highly debated.

The Isua supracrustal belt (ISB) hosts unusually well-preserved Eoarchean crustal rocks that experienced greenschist metamorphism. Peak metamorphic temperatures $\left(<400^{\circ} \mathrm{C}\right)$ in the northern ISB suggest primary magnetic signatures may be preserved by magnetite given its $580^{\circ} \mathrm{C}$ Curie point.

We conducted baked contact tests where mafic dykes intrude banded iron formation (BIF). The BIF contains a magnetite-bearing natural remanent magnetization (NRM) that persists up to $580^{\circ} \mathrm{C}$ during thermal demagnetization. Results suggest the NRM in the BIF preceded dyke emplacement and was likely acquired during diagenetic magnetite formation and/or thermal metamorphism. U-Pb ages in the BIF indicate the magnetite crystallized at $\sim 3.7 \mathrm{Ga}$. Our thermal diffusion experiments indicate a closure temperature for the $\mathrm{U}-\mathrm{Pb}$ system in magnetite of $580-600^{\circ} \mathrm{C}$, suggesting the stable component of the NRM in the BIF formed at $3.7 \mathrm{Ga}$. These results hint the ISB may contain the oldest record of Earth's field. 